Research letter

\title{
Simultaneous surgical correction of atrial fibrillation and aortic valve replacement: immediate results after surgery
}

\author{
Leo A. Bockeria, Olga L. Bockeria, Merab K. Sanakoev, Tatyana G. Le, Anna S. Satyukova, Artak Yu. Ispiryan, \\ Igor Ya. Klimchuk, Zamik F. Fatulaev, Andrey D. Petrosyan, Vladimir A. Shvartz
}

Bakoulev Scientific Center for Cardiovascular Surgery, Moscow, Russia

Received 16 September 2016, Revised 15 November 2016, Accepted 30 November 2016

(C) 2016, Bockeria L.A., Bockeria O.L., Sanakoev M.K., Le T.G., Satyukova A., Ispiryan A.Yu., Klimchuk I.Ya., Fatulaev Z.F., Petrosyan A.D., Shvartz V.A. (C) 2016, Russian Open Medical Journal

Abstract: Aim - To assess the results of simultaneous surgical correction of atrial fibrillation and aortic valve replacement.

Materials and Methods - The retrospective analysis was held for the period of 2009-2016 of patients with atrial fibrillation (AF) and pathology of the aortic valve after combined operations. 68 patients were included in the study, the average age was 56 (51; 64$)$ years; men $53 \%$, women $47 \%$. All patients were in III-IV functional class by NYHA classification. The duration of AF was 34 (24; 58 ) months. AF: persistent in $70,6 \%$, paroxysmal in $29,4 \%$. Calculated risks comprised: Euro Score II $-3,8(2,4 ; 5,6)$, the risk of in-hospital mortality and the risk of total mortality by Ambler - $5,5(3 ; 7,3)$ and $8(6 ; 9)$, respectively.

Results - The average number of simultaneous procedures per one patient was $-4(4 ; 4)$, minimum -3 , maximum -5 . In $100 \%$ cases was performed aortic valve and mitral valve correction and Maze IIIB procedure. CABG was performed in 20,6\% of cases and tricuspid valve repair was performed in $67,6 \%$. The total duration of operations was $6.3 \pm 1.4$ hours, the time of CPB: 208 (168; 224) min, aortic clamping time: $126(119 ; 151) \mathrm{min}$. In-hospital mortality was $4.4 \%$. The main non-lethal complications in the early postoperative period were heart failure, respiratory and renal insufficience, hemorrhage and transient neurological disorder.

Conclusions - There are few data demonstrating experience in performing of such complex surgical cases due to the severity of patients and small number of institutions having such experience. In our series of hospital mortality observations correlated with the calculated and accounted for $4.4 \%$, which is an acceptable result in this group of patients.

Keywords: atrial fibrillation, aortic valve replacement, multivalve pathology of the heart.

Cite as Bockeria LA, Bockeria OL, Sanakoev MK, Le TG, Satyukova AS, Ispiryan AYu, Klimchuk IY, Fatulaev ZF, Petrosyan AD, Shvartz VA. Simultaneous surgical correction of atrial fibrillation and aortic valve replacement: immediate results after surgery. Russian Open Medical Journal 2016; 5: e0404.

Correspondence to Vladimir A. Shvartz. Address: 135, Rublevskoe shosse, Moscow, 121552, Russia. E-mail: shvartz.va@ya.ru

\section{Introduction}

The modern improvement of surgical, anesthetic and resuscitation technology allows us to expand the indications and surgical activity for the cohort of patients with complex comorbidities of heart and blood vessels.

Surgical interventions with combined heart disease still remains one of the most complex and incompletely understood problem of modern cardiac surgery. There is a category of patients who have long-term existence of the main process, which results in multivalve disease and occurrence of atrial fibrillation (AF). Such patients initially have complex intra cardiac hemodynamics and severe general condition because of myocardial damage due to arrhythmogenic cardiomyopathy and high risk of thrombotic complications $[1,2]$.

According to the reported data hospital mortality of the correction of comorbidity without AF varies from $11 \%$ to $50 \%$ [3, 4]. In this regard, many surgeons are trying to minimize the trauma and cardiopulmonary bypass time, ignoring AF. Nowadays combined correction of multivalve disease with AF is rarely performed [5]. According to various data, the absence of surgical treatment of $\mathrm{AF}$ in patients with combined heart pathology reaches about $40-60 \%$, leaving them at increased risk of stroke [6, 7].

The aim of the study is to assess the results of simultaneous surgical correction of the aortic valve pathology and AF.

\section{Material and Methods}

Patients

A retrospective analysis of patients' disease histories, operated in the Department of Surgical Treatment of Interactive Pathology (Bakoulev Scientific Center for Cardiovascular Surgery, Moscow, Russia) during the period 2009-2016 have been performed. The disease histories were selected in the archive in accordance with the criteria of inclusion of all the interventions made in the department during thisperiod. 
Table 1. Clinical and instrumental characteristics of patients

\begin{tabular}{|c|c|}
\hline Parameter & Value $(n=68)$ \\
\hline Age, years & $56(51,64)$ \\
\hline \multicolumn{2}{|l|}{ Gender, \%: } \\
\hline - Male & 53 \\
\hline - Female & 47 \\
\hline Body mass index, $\mathrm{kg}, \mathrm{M} \pm \mathrm{SD}$ & $26 \pm 3.8$ \\
\hline AF duration, month & $34(24,58)$ \\
\hline \multicolumn{2}{|l|}{ AF form, \%: } \\
\hline - Paroxysmal & 29.4 \\
\hline - Persistent & 4,4 \\
\hline - Long persistent & 66.2 \\
\hline Coronary heart disease, $\%$ & 29.4 \\
\hline Prior miocardial infarction, \% & 19.1 \\
\hline COPD, $\%$ & 5.9 \\
\hline Hypertension, \% & 64.7 \\
\hline Diabetes mellitus, \% & 5.9 \\
\hline Prior stroke, \% & 16.2 \\
\hline EuroScore II risk, \%, Me (Q1, Q3) & $3.8(2.4,5.6)$ \\
\hline Risk of in-hospital mortality by Ambler, \%, Me (Q1, Q3) & $5.5(3.0,7.3)$ \\
\hline Risk of total mortality by Ambler, \%, Me (Q1, Q3) & $8.0(6.0,9.0)$ \\
\hline Left ventricular ejection fraction, \%, Me (Q1, Q3) & $59(55 ; 67)$ \\
\hline LA (med.-lat.), cm, Me (Q1, Q3) & $5.5(5.3,5.9)$ \\
\hline LA (ant.-post.), cm, Me (Q1, Q3) & $6.0(5.8,7.0)$ \\
\hline ESV, ml, Me (Q1, Q3) & $53(43,70)$ \\
\hline $\mathrm{EDV}, \mathrm{ml}, \mathrm{M} \pm \mathrm{SD}$ & $161.0 \pm 45.0$ \\
\hline Mitral valve annulus, mm, Me (Q1, Q3) & $40(37,40)$ \\
\hline Tricuspid valve annulus, mm, Me (Q1, Q3) & $36(34,39)$ \\
\hline
\end{tabular}

COPD, chronic obstructive pulmonary disease; LA, left atrium; ESV, endsystolic volume; EDV, end-diastolic volume.
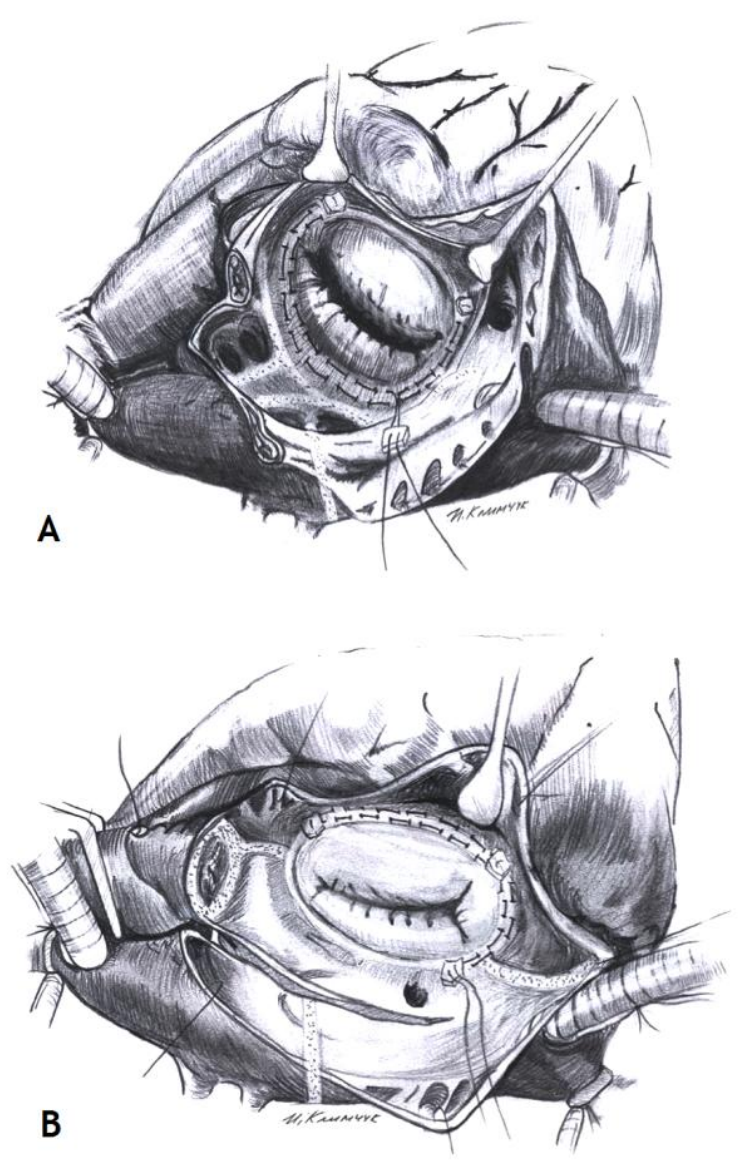

Figure 1. A) Suture annuloplasty of the mitral valve; B) Tricuspid valve plasty by De Vega.
Inclusion criteria: i) all cases of complex surgical pathology, which required multiple surgical procedures; ii) simultaneous intervention on the aortic valve in combination with a surgical correction of AF (Maze IIIB procedure). In addition to listed procedures, the study also included patients with coronary artery bypass grafting (CABG), mitral valve correction, tricuspid valve correction and correction of congenital and acquired diseases.

During the period of 2009-2016, 68 patients underwent such interventions. Table 1 shows the clinical and instrumental characteristics of patients included in our study. The age of this patients was $56(51,64)$ years (data presented as median with interquartile range). Gender balance: men $-53 \%$, women $-47 \%$.

All patients in addition to aortic valve disease had AF. In 70,6\% of cases, there was persistent form of AF. The average duration of a history of AF was about 3 years: $34(24,58)$ months (data presented as median with interquartile range). As a comorbidity we should note the following: about half of the patients had hypertension (64.7\% patients), $19.1 \%$ suffered from myocardial infarction, $16.2 \%$ suffered from cerebral stroke/or other cerebrovascular disease. There have also been chronic obstructive pulmonary disease, diabetes, etc. (Table 1).

The risk by Eurocore II was 3.8\%, interquartile spread from $2.4 \%$ to $5.6 \%$. This data considered the group of patients to an average risk. However, it does not take into consideration the severity of the surgery and its complexity. In this regard, we additionally used the adapted calculator to account the risks in the proposed multi-component operations, which has been suggested by $\mathrm{G}$. Ambler et al. This calculator also takes into considerationthe additional surgical procedures (CABG, Maze procedure, etc.). According to this calculator estimated risks of hospital mortality and total mortality were $5.5(3.0,7.3)$ and $8(6,9)$ respectively (data presented as median with interquartile range).

In general, in the group of patients was the intact left ventricular ejection fraction, enlarged fibrous rings of the atrioventricular valves, increased size of the left atrium (Table 1 ).

The etiology of aortic valve pathology was following: congenital $-38.2 \%$, aqired $61.8 \%$. The etiology of other valve pathology was following: rheumatic valve pathology was in $85,3 \%$ cases, degenerative diseases of connective tissue in $5.9 \%$ of cases, congenital abnormality of the valve in $5.9 \%$ of cases and infectious endocarditis of the valves in $2,9 \%$ of cases.

\section{Technique of the operations}

All operations were performed through a median sternotomy with cardiopulmonary bypass, hypothermia $28^{\circ} \mathrm{C}$ and cardioplegia.

First, the surgical correction of arrhythmia Maze IIIB procedure has been performed and after that the surgical correction of valve pathology came.

In all cases, we used mechanical prostheses, which were implanted using a U-shaped seam. In reconstructive operations on the valves, we used the following methods: marginal resection of the aortic valve leaflets, the mitral valve suture annuloplasty, tricuspid valve plastic by De Vega (Figure 1). In the case of coronary disease, the procedure began with the imposition of distal anastomoses. 


\section{Statistical analysis}

Initially the normal distribution of obtained parameters both quantitative and qualitative was defined. We used the most rigorous criteria - W Shapiro-Wilk test. It was found that the data structure partially was not described by a normal distribution. Therefore, further studies of the dependencies were carried out by parametric and non-parametric methods of statistics. Correlation negotiations were estimated by Spearman rank correlation coefficient. To identify predictors of complications after surgery we used discriminant analysis. The data was presented as mean with standard deviation, $M \pm S D$, in the normal distribution of values or median with interquartile range, Me (Q1, Q3), in the distribution of values that was different from normal. The reliability of the statistical evaluation was not less than $95 \%$. We used Microsoft Office Excel 2007 software packages, STATISTICA 10.0 (Statsoft, USA).

\section{Results}

Table 2 shows the results of operations. The average duration of the operation was more than 6 hours.

The cardiopulmonary bypass time and aortic clamping were also prolonged, which logically explained by the expanded volumes of surgery.

Most patients underwent 4 different types of interventions. The minimum number of interventions was 3 (aortic valve correction, mitral valve correction, Maze IIIB procedure); maximum - 5 (aortic valve correction, mitral valve correction, tricuspid valve correction, Maze IIIB procedure and CABG).

Table 2 lists the main non-lethal postoperative complications $(n=27)$, whichwere observed in the study group at the in-hospital stage.

The most common complication was heart failure, the manifestation of which was the hypotension that required cardiotonic support in high doses on the first day after surgery. For this reason, the $13.3 \%$ of cases required the intra-aortic balloon counterpulsation.

Heart failure was the main cause of death in 3 patients, which determined the hospital mortality in this group of $4.4 \%$.

Respiratory insufficiency was a complication resulted by the delayed artificial lung ventilation for more than 48 hours. Nearly a third part of patients in this group was complicated by respiratory insufficiency without any initially existing pathology of the respiratory system.

Other complications were relatively rare and have been corrected in the intensive care units in first two days of stay.

In the early postoperative period, $14.7 \%$ of patients required implantation of cardiac pacemaker. The main reason for implantation of pacemaker was sick sinus syndrome.

At the moment of discharge of the patient we observed sinus rhythm in 62 patients that amounted $91.2 \%$.

The average stay in the intensive care unit was 3 days $(2,5)$, the total hospital stay $-16(12,20)$.

Between the indicators "day bed in the intensive care unit" and "risk of hospital mortality by Ambler" correlation was $r=0.87$, $\mathrm{P}<0.05$; between indicators of "total bed-day" and "risk of hospital mortality by Ambler» $r=0.74, P<0.05$.

Discriminant analysis revealed three indicators that show a statistically significant $(p<0,0212)$ multiply associated with the development of postoperative complications (Table 3).
Table 2. Surgical indicators and indicators of non-lethal postoperative complications

\begin{tabular}{lc}
\multicolumn{1}{c}{ Parameter } & Value $(n=68)$ \\
\hline Total duration, h, M \pm SD & $6.3 \pm 1.4$ \\
Artificial circulation time, minutes, Me (Q1, Q3) & $208(168,224)$ \\
Aortic clamping time, min & $126(119,151)$ \\
Aortic valve replacement, \%: & 100 \\
Mitral valve correction, \%: & \\
- replacement & 79.4 \\
- repair & 20.6 \\
Maze IIIB procedure, \% & 100 \\
Tricuspid valve correction, \% & 67.6 \\
Left atrium appendage correction, \% & 48.5 \\
CABG, \% & 19.1 \\
Other intervention, \% & 5.9 \\
The number of simultaneous interventions, Me (Q1, Q3) & $4(4,4)$ \\
Indicators of non-lethal postoperative complications & Value ( $n-27)$ \\
Bleeding, \% & 11.1 \\
Neurological disturbances, \% & 11.1 \\
Renal insufficiency, \% & 7.4 \\
Respiratory insufficiency, \% & 29.6 \\
Heart failure, \% & 48.2 \\
RFA, radiofrequency ablation; CABG, coronary artery bypass grafting.
\end{tabular}

Table 3. The results of discriminant analysis of connection between complications and clinical indicators $(F(14,17)=2,858, p<0,0212)$.

\begin{tabular}{lcccc}
\hline \multicolumn{1}{c}{ Parameter } & $\begin{array}{c}\text { Wilks' } \\
\text { Lambda }\end{array}$ & $\begin{array}{c}\text { Partial } \\
\text { Lambda }\end{array}$ & $\mathrm{F}$ & p-level \\
\hline COPD & 0,412 & 0,723 & 6,508 & $\mathbf{0 , 0 2 0}$ \\
Creatinine & 0,402 & 0,740 & 5,925 & $\mathbf{0 , 0 2 6}$ \\
AF duration & 0,377 & 0,789 & 4,530 & $\mathbf{0 , 0 4 0}$ \\
Prior stroke & 0,343 & 0,868 & 2,572 & 0,127 \\
Age & 0,335 & 0,888 & 2,131 & 0,162 \\
Hypertension & 0,335 & 0,888 & 2,125 & 0,163 \\
Chronic heart failure & 0,323 & 0,923 & 1,411 & 0,251 \\
Other & & & & \\
\hline
\end{tabular}

COPD, chronic obstructive pulmonary disease.

\section{Discussion}

It is known that mostly during the natural course of the heart disease, especially valve pathology, the condition of a patient stays compensated for some time. During this period, the patient may have no symptoms. Onset of symptoms usually associated with decompensation of the disease and the disorder of any of the functions of the heart. The most noticeable symptoms are AF and reduction in cardiac pump function. Heart failure is the outcome of any heart disease.

In this study, the analysis of a group of patients who have several organic heart diseases led to total cardiac decompensation and manifestation of different symptoms. However, the common complication of every pathology was AF. The aim of surgical correction consisted in eliminating all organic substrates of the diseases, as well as the elimination of AF. It should be noted that not every surgeon consider rational elimination of AF in the presence of a several cardiac pathologies, because it lengthens the time of aortic clamping and the total time of the artificial circulation. Our philosophy is that the presence of the arrhythmia and its long persistence even in structurally normal heart results in the development of arrhythmogenic cardiomyopathy. It is shown that in patients with isolated AF occurs dilatation of the mitral and 
tricuspid valves rings, expansion of the cavities of the heart and increase the pressure in the pulmonary artery, which even in normal pumping function of the heart is considered to be a sign of heart failure.

It should be noted that the restoration of normal heart rhythm in the severe group of patients with a number of associated heart problems is one of the fundamental factors of further recovery. The AF recurrence after surgery significantly reduces the likelihood of positive long-term results of the operation. The presence of atrial fibrillation leads to further progression of arrhythmogenic cardiomyopathy and returns the dilation of the heart cavities, which resultagain in valves dysfunction and progression of heart failure.

In our study, hospital mortality was $4.4 \%$, which is a good result, comparable to those of other authors, representing the experience of treatment of such cohort of patients in current literature [8-10].

In this regard, an important item remains a risk assessment and a detailed analysis of the clinical outcomes of surgical interventions in this group of patients [11, 12].

\section{Conflict of interest}

The authors declared no potential conflicts of interest with respect to the research, authorship, and/or publication of this article.

\section{Acknowledgement}

This study was supported by Ministry of Education and Science of the Russian Federation within a program "Development of Model of a MicroElectromechanical Systems (MEMS) to Transform the Kinematic Activity of the Heart into Electric Energy for the Use in High-Tech Cardiac Surgery" (Agreement No. 14.607.21.0021, Reference No. 2014-14-579- 0001-066, Unique Identification of Applied Research RFMEFI60714X0021).

\section{References}

1. Weimar T, Gaynor SL, Seubert DY, Damiano RJ Jr, Doll N. Performing the Left AtrialMaze Ablation Pattern Without Atriotomy. Ann Thorac Surg 2016; 101(2): 777-779. DOI: 10.1016/j.athoracsur.2015.05.137.

2. Lawrance $\mathrm{CP}$, Henn MC, Damiano RJ Jr. Concomitant Cox-Maze IV techniques during mitral valve surgery. Ann Cardiothorac Surg 2015; 4(5): 483-486. DOI: 10.3978/j.issn.2225-319X.2014.12.06.

3. Gamzaev AB, Dobrotin SS, Pichugin VV, Zemskova EN, Medvedev AP, Chiginev VA. Surgical approach for the correction of multi-valve heart defects. Patologiya Krovoobrashcheniya i Kardiokhirurgiya 2006; (4): 21-25. Russian

4. Prokopchuk EF, Novikov VK, Bondarenko BB. Results of surgical treatment of multi-valve heart defects in patients with a high degree of risk. Patologiya Krovoobrashcheniya i Kardiokhirurgiya 1998; (1): 3133. Russian

5. Joshibayev SD, Bolatbekov BA. One-stage application of mitral valve correction, surgical radiofrequency ablation and left atrial atrioplasty. Annals of the Russian Academy of Medical Sciences 2015; 70(3): 279285. Russian. DOI: 10.15690/vramn.v70i3.1323.

6. Ad N, Holmes SD, Pritchard G, Shuman DJ. Association of operative risk with the outcome of concomitant Cox Maze procedure: a comparison of results across risk groups. I Thorac Cardiovasc Surg 2014; 148(6): 3027-33. DOI: 10.1016/j.jtcvs.2014.05.039.

7. Bockeria OL, Shvartz VA, Akhobekov AA, Glushko LA, Le TG, Kiselev AR, et al. Statin therapy in the prevention of atrial fibrillation in the early postoperative period after coronary artery bypass grafting: A metaanalysis. Cor et Vasa 2016. [in press] DOI: 10.1016/j.crvasa.2016.11.003.
8. Gillinov AM, Gelijns AC, Parides MK, DeRose JJ Jr, Moskowitz AJ, Voisine $P$, et al. Surgical ablation of atrial fibrillation during mitral-valve surgery. N Engl J Med 2015; 372(15): 1399-1409. DOI: 10.1056/NEJMoa1500528.

9. Cox JL. Surgical ablation for atrial fibrillation. N Engl J Med 2015; 373: 483-484. DOI: 10.1056/NEJMc1506893.

10. Henn MC, Lancaster TS, Miller JR, Sinn LA, Schuessler RB, Moon MR, et al. Late outcomes after the Cox maze IV procedure for atrial fibrillation. J Thorac Cardiovasc Surg 2015; 150(5): 1168-1176, 1178.e1-2. DOI: 10.1016/j.jtcvs.2015.07.102.

11. Bockeria LA, Mironenko MYu, Mironenko VA, Klimchuk IYa, Dzhobava ER. Severe mitral and tricuspidal regurgitation arising from isolated annular dilatation associated with atrial fibrillaton. Annaly Aritmologii 2016; 13(1): 23-28. Russian. DOI: 10.15275/annaritmol.2016.1.3.

12. Bockeria LA, Bockeria OL, Shvartz VA, Sanakoev MK, Ispiryan AY, Fatulaev ZF, T.G. Le. The immediate results of simultaneous surgical correction of complex heart disease with concomitant atrial fibrillation. Novosti Khirurgii 2016; Vol 24 (3): 227-233. doi: 10.18484/2305-0047.2016.3.227.

\section{Authors:}

Leo A. Bockeria - MD, D.Sc., Professor, Academician the Russian Academy of Sciences, Director of Bakoulev Scientific Center for Cardiovascular Surgery, Moscow, Russia.

Olga L. Bockeria - MD, D.Sc., Professor, Corresponding Member of the Russian Academy of Sciences, Principal Researcher, Department of Surgical Treatment for Interactive Pathology, Bakoulev Scientific Center for Cardiovascular Surgery, Moscow, Russia.

Merab K. Sanakoev - MD, PhD, Cardiovascular Surgeon, Department of Surgical Treatment for Interactive Pathology, Bakoulev Scientific Center for Cardiovascular Surgery, Moscow, Russia.

Tatyana G. Le - MD, Cardiologist, Junior Researcher, Department of Surgical Treatment for Interactive Pathology, Bakoulev Scientific Center for Cardiovascular Surgery, Moscow, Russia.

Anna S. Satyukova - MD, Cardiologist, Junior Researcher, Department of Surgical Treatment for Interactive Pathology, Bakoulev Scientific Center for Cardiovascular Surgery, Moscow, Russia.

Artak Yu. Ispiryan - MD, Cardiologist, Cardiovascular Surgeon, Department of Surgical Treatment for Interactive Pathology, Bakoulev Scientific Center for Cardiovascular Surgery, Moscow, Russia.

Igor Ya. Klimchuk - MD, Cardiovascular Surgeon, Department of Surgical Treatment for Interactive Pathology, Bakoulev Scientific Center for Cardiovascular Surgery, Moscow, Russia.

Zamik F. Fatulaev - MD, PhD, Cardiovascular Surgeon, Department of Surgical Treatment for Interactive Pathology, Bakoulev Scientific Center for Cardiovascular Surgery, Moscow, Russia.

Andrey D. Petrosyan - MD, Cardiovascular Surgeon, Department of Surgical Treatment for Interactive Pathology, Bakoulev Scientific Center for Cardiovascular Surgery, Moscow, Russia.

Vladimir A. Shvartz - MD, PhD, Cardiologist, Researcher, Department of Surgical Treatment for Interactive Pathology, Bakoulev Scientific Center for Cardiovascular Surgery, Moscow, Russia. 